\title{
openheart Acarbose: safe and effective for lowering postprandial hyperglycaemia and improving cardiovascular outcomes
}

\author{
James J DiNicolantonio, ${ }^{1}$ Jaikrit Bhutani, ${ }^{2}$ James H O'Keefe ${ }^{1}$
}

To cite: DiNicolantonio JJ, Bhutani J, O'Keefe JH. Acarbose: safe and effective for lowering postprandial hyperglycaemia and improving cardiovascular outcomes. Open Heart 2015;2:e000327. doi:10.1136/openhrt-2015000327

Received 12 August 2015 Revised 23 September 2015 Accepted 27 September 2015
CrossMark

\footnotetext{
${ }^{1}$ Saint Luke's Mid America Heart Institute, Kansas City, Missouri, USA

2Pt BD Sharma PGIMS, Rohtak, Haryana, India
}

Correspondence to Dr James J DiNicolantonio; jjdinicol@gmail.com

\section{ABSTRACT}

$\alpha$-Glucosidase inhibitors (AGIs) are a class of oral glucose-lowering drugs used exclusively for treatment or prevention of type 2 diabetes mellitus. AGIs act by altering the intestinal absorption of carbohydrates through inhibition of their conversion into simple sugars (monosaccharides) and thus decrease the bioavailability of carbohydrates in the body, significantly lowering blood glucose levels. The three AGIs used in clinical practice are acarbose, voglibose and miglitol. This review will focus on the cardiovascular properties of acarbose. The current available data suggest that AGIs (particularly acarbose) may be safe and effective for the treatment of prediabetes and diabetes.

\section{INTRODUCTION}

Currently, there are many different classes of medications to treat diabetes, such as biguanides (metformin), sulfonylureas, insulin, glucagon-like peptide 1 (GLP-1) agonists, dipeptidyl peptidase IV inhibitors, thiazolidinediones and sodium-glucose transporter 2 inhibitors (to name a few). However, $\alpha$-glucosidase inhibitors (AGIs) are another class of antidiabetic medications, albeit rather neglected, in the treatment of prediabetes/diabetes. Despite this fact, acarbose has recently been recommended in certain guidelines for treating diabetes, receiving preferred status even when compared to other oral glucose lowering drugs, due to its proven ability to reduce cardiovascular events. Additionally, acarbose has minimal risk for hypoglycaemia and, when titrated slowly, is generally well tolerated despite occasional gastrointestinal side effects such as flatulence. Acarbose has also been found to improve vascular health and also likely has antiplatelet effects. Lastly, acarbose has been shown to provide euglycaemia, partially by increasing GLP-1 levels and blunting postprandial spikes of glucose and lipid levels.

\section{MECHANISM OF ACTION}

AGIs behave as pseudocarbohydrates in the intestine. ${ }^{1}$ They act through competitive inhibition of $\alpha$-glucosidase enzymes found in the brush border of gut epithelium. These enzymes facilitate the conversion of poorly absorbable oligosaccharides and polysaccharides to monosaccharides, which are easily absorbed in the intestine.

Acarbose, a pseudo-tetrasaccharide, possesses nitrogen between the first and second glucose molecule. This modification bestows acarbose with a particularly high affinity for the $\alpha$-glucosidase enzyme. ${ }^{2}$ The binding affinity and inhibition capacity of acarbose for various glucosidases is listed here in descending order: maltase-glucoamylase, followed by sucrase, maltase and dextranase. Acarbose does not inhibit $\beta$-glucosidases such as lactase. ${ }^{3}$

\section{SURROGATE END POINTS Glycaemia}

Foods containing starch, particularly refined carbohydrates such as white flour, generally provide a large percentage of the total daily caloric intake among cultures in the Western world. ${ }^{4}$ Carbohydrates, in general, differ substantially in their physiological and metabolic effects, depending on their source (eg, whole foods vs manufactured, processed and highly refined foods), and thus have varying health effects. ${ }^{5}$ Carbohydrates are often categorised on the basis of their glycaemic response, with low glycaemic index foods generally being considered helpful in the prevention of diabetes, ${ }^{6} 7$ coronary heart disease $^{89}$ and obesity. ${ }^{10} 11$ The rate of carbohydrate digestion and the subsequent absorption with resultant spiking of blood glucose is the key factor affecting the glycaemic index. Low glycaemic index foods are created by different processing methods, such as adding highly viscous soluble fibre (eg, glucomannan), or amylase-inhibitory 
phytochemicals such as those extracted from the white kidney bean. AGIs mimic these compounds in that they decrease the glycaemic index (as well as the glycaemic load) of carbohydrate-rich foods. ${ }^{12-20}$

Microvascular and macrovascular complications in type 2 diabetics are better linked with postprandial hyperglycaemia than fasting glucose. ${ }^{21} 22$ Also, postprandial hyperglycaemia is a marker of vascular risk in nondiabetics who cannot tolerate glucose. ${ }^{9}{ }^{10}$ The pro-oxidative adverse effect of postprandial glycaemic excursions may be responsible for this cardiovascular risk. Moreover, glycaemic fluctuations, coupled with elevated free fatty acids, have a pro-oxidant effect on $\beta$ cells of the pancreas. This can be especially dangerous in prediabetics compared to insulin-sensitive individuals, as it leads to $\beta$-cell exhaustion, which can precipitate overt clinical diabetes. ${ }^{23}$ Hence, the effect of acarbose to blunt postprandial hyperglycaemia may aid in preventing type 2 diabetes mellitus (T2DM) or delay its onset.

Wachters-Hagedoorn et $a l^{24}$ demonstrated that the peak glucose concentration and area under curve (AUC) from 0 to $120 \mathrm{~min}$ was significantly lower for corn pasta with acarbose (CPac) $(6.0 \pm 0.2 \mathrm{mmol} / \mathrm{L})$ versus CP (corn pasta alone) $(6.7 \pm 0.3 ; \mathrm{p}=0.007)$ and CPac $(25.7 \pm 7.1 \mathrm{mmol} / \mathrm{L} / 2 \mathrm{~h})$ than for CP $(65.3 \pm 17.3$; $\mathrm{p}=0.034$ ), respectively. Acarbose was also shown to significantly reduce the percentage of administered dose excreted as ${ }^{13} \mathrm{CO}_{2}$ in breath (CP $37.5 \pm 2.8$ cum \%dose/ $6 \mathrm{~h}$ vs $\mathrm{CPac} 27.2 \pm 2.2 ; \mathrm{p}=0.004$ ) over the $360 \mathrm{~min}$ post-test meal.

A Cochrane meta-analysis found that acarbose therapy reduced glycated haemoglobin (HbAlc) levels by a mean of $0.8 \%$. This decrease was accentuated in individuals with higher baseline HbA1C levels (baseline HbA1c of $<7 \%, 7-9 \%$, and $>9 \%$ had decreases of $0.56 \%$ (95\% CI 0.36 to 0.76$), 0.78 \%$ (95\% CI 0.63 to 0.93$)$ and $0.93 \% \quad(95 \%$ CI 0.53 to 1.33$)$, respectively). A meta-regression analysis revealed regression coefficient of -0.12 ( $95 \%$ CI -0.26 to 0.03 ), showing an additional $0.12 \%$ decrease in $\mathrm{HbA1c}$ for every $1 \%$ increase in baseline HbAlc. Moreover, acarbose was shown to reduce fasting blood glucose by $1.09 \mathrm{mmol} / \mathrm{L}$ (28 comparisons; $95 \%$ CI 0.83 to 1.36 ) and $1 \mathrm{~h}$ postprandial glucose by $2.32 \mathrm{mmol} / \mathrm{L}$ (acarbose; 22 comparisons; 95\% CI 1.92 to 2.73). ${ }^{11}$

The glycaemic effect of acarbose on HbAlc did not vary with dose, however, acarbose did decrease postprandial glucose in a dose-dependent manner. Acarbose 50, 100, 200 and $300 \mathrm{mg}$ three times a day reduced HbA1c by $0.90,0.76,0.77$ and $0.78 \%$, respectively, and postprandial glucose by $1.63,2.26,2.78$ and $3.62 \mathrm{mmol} / \mathrm{L}$, respectively. ${ }^{11}$ This glycaemic benefit of acarbose has been more significant in Asian trials than those in the West, due to predominant consumption of a carbohydrate-rich diet among Asian populations. ${ }^{25}$

The minimal efficacy of acarbose on HbAlc, as described by a UK-Prospective Diabetes Study trial with a reduction of $0.5 \%$, could be an underestimation. In this trial, acarbose was an add-on therapy at the end of study while the patients were pretreated for 8 years with antidiabetic medications. Also, this study experienced high drop-out rates. ${ }^{26}$

\section{Oxidative effects, endothelial dysfunction and vascular damage}

Glucose excursions can lead to the formation of reactive oxygen species (ROS) such as superoxide, which leads to oxidative stress in the body. ${ }^{27}$ People with diabetes have been shown to have increased plasma concentrations of superoxide anions, which also vary in direct proportion with blood glucose levels. ${ }^{28}$ This oxidative damage may be responsible for the development of endothelial dysfunction, reduced flow-mediated vasodilation (FMVD) and microvascular and macrovascular complications.

The four main pathways involved in hyperglycaemia-induced vascular damage include: (1) activation of protein kinase $\mathrm{C}$ (PKC); (2) advanced glycation end (AGE) product formation and increased flux through; (3) polyol; and (4) hexosamine pathways. ${ }^{27}$ The RAGE (receptor for AGE products) ligation and effects of hyperglycaemia on the electron transport chain (ETC) lead to formation of ROS. ${ }^{29}{ }^{30}$ Hyperglycaemia increases the electron flow in the Kreb's cycle, thus accumulation of nicotinamide adenine dinucleotide (NADH) and flavin adenine dinucleotide (FADH2), and an increased proton transport via the inner mitochondrial membrane. This inhibits the ETC and prolongs the half-life of free radicals. These free radicals interact with oxygen and cause superoxide anion overproduction. ${ }^{27}$

Marfella $e t a l^{31}$ demonstrated the effect of glucose excursions on plasma nitrotyrosine levels, markers of oxidative damage. Nitrotyrosine levels were unchanged in states of euglycaemia $(5 \mathrm{mmol} / \mathrm{L}$ for $120 \mathrm{~min})$ while hyperglycaemic states $(15 \mathrm{mmol} / \mathrm{L}$ for $120 \mathrm{~min})$ caused increased nitrotyrosine levels and increased blood pressure. Further research by Ceriello et $a l^{32}$ showed that oral glucose tolerance test (OGTT) in people with and without diabetes blunted antioxidant mechanisms, as assessed by total radical trapping antioxidant parameter (TRAP). TRAP levels were significantly lower in people with diabetes compared to those without diabetes $(660.3$ +46 vs $832.6+56 \mu \mathrm{mol} / \mathrm{L}, \mathrm{p}<0.03)$ and TRAP was significantly reduced in both groups following the OGTT. Similar findings were demonstrated after a meal. Nitrotyrosine levels were measured after standard meal tests in 23 people with T2DM and 15 matched controls. The former group received two standard meals-one 30 min prior to regular insulin (Actrapid) and the other with insulin aspart. This was carried out to evaluate postprandial hyperglycaemia. The results revealed a linear correlation between postprandial hyperglycaemia and nitrotyrosine levels. Insulin aspart reduced postprandial glucose excursion $(p<0.03)$ and nitrotyrosine levels $(\mathrm{p}<0.03)$ as compared to regular insulin. ${ }^{33}$ The above 
findings clearly depict acute hyperglycaemia as a driver of oxidative stress, particularly in type 2 diabetics.

Kawano et al compared FMVD of the brachial artery in response to an OGTT in individuals with IGT $(n=24)$ and normal individuals $(\mathrm{n}=17)$. FMVD at baseline was $7.53+0.40 \%, 6.40+0.48 \%$ and $4.77+0.37 \%$ in the controls, IGT and diabetes groups, respectively. After $1 \mathrm{~h}$, the FMVD was reduced by $43.7 \% \quad(p>0.05), \quad 78.5 \%$ $(\mathrm{p}<0.005)$ and $71.7 \%(\mathrm{p}<0.005)$ in the controls, IGT and diabetes groups, respectively. Further, at $2 \mathrm{~h}$, it was reduced by $15.7 \%(p>0.05), 38.5 \%(p<0.01)$ and $73 \%$ $(\mathrm{p}<0.005)$, respectively. The progressive decline and a significant inverse correlation between FMVD and glucose levels were observed $(\mathrm{r}=-0.62, \quad \mathrm{p}<0.01)$. Furthermore, plasma levels of thiobarbituric acid, another marker of oxidative damage, correlated positively with FMVD $(\mathrm{r}=-0.58, \mathrm{p}<0.01){ }^{34}$

Postprandial hyperglycaemia has also been shown to cause an adverse increase in carotid intimal medial thickness (IMT), irrespective of adjustment for associated risk factors. ${ }^{35-37}$ Benefits of acarbose on carotid IMT were evaluated in a subgroup of the Stop noninsulin dependent diabetes mellitus (STOP-NIDDM) trial, which revealed a significant reduction in the progression of IMT-mean in the acarbose versus placebo group. The acarbose cohort had an IMT-mean increase of $0.02(0.07) \mathrm{mm}$ versus $0.05(0.06) \mathrm{mm}$ in the placebo cohort, after a mean duration of 3.9 years $(p=0.027) .^{38}$ Acarbose therapy reduced the yearly IMT-mean increase by $\approx 50 \%{ }^{38}$ which was further reduced to that observed in participants with normal glucose tolerance. ${ }^{39}$

Further, Esposito et at $t^{40}$ showed that in individuals with both normal $(n=20)$ and IGT $(n=15)$ intravenous glucose pulses caused a significantly greater increase in mediators of subclinical inflammation (interleukin-6 and tumour necrosis factor- $\alpha$ ) as compared to sustained hyperglycaemic periods. Also, oxidative stress causes upregulation of soluble adhesion molecules, facilitating leucocyte adhesion to endothelium thus initiating atherogenesis. Significantly increased levels of plasma intracellular adhesion molecule-1 (ICAM-1) were observed post-OGTT in people with T2DM. This increase was blunted by supplementation of glutathione during the OGTT. ${ }^{41}$ A further crossover study of 10 patients with T2DM indicated that supplementation with L-arginine provided overnight euglycaemia as well as reduced plasma ICAM-1 levels. ${ }^{42}$ This evidence supports the hypothesis that hyperglycaemia is a key mediator in altering the homeostasis of adhesion molecules, subclinical inflammation and atherosclerosis.

Acarbose has been demonstrated to prevent postprandial hyperglycaemia induced acute endothelial dysfunction. ${ }^{43}{ }^{44}$ Recently, Santilli et al evaluated the effects of acarbose on markers of lipid peroxidation and platelet activation (8-iso-prostaglandin (PG)F2 $\alpha$, 11-dehydrothromboxane (TX)B2, plasma CD40 ligand and plasma P-selectin). The acarbose group $(\mathrm{n}=25)$ had a significantly greater reduction in 11-dehydro-TXB2 levels (by
$40 \%$ vs baseline) versus the placebo group $(n=23)$ (mean change -0.23 vs $0.031 \mathrm{log} \mathrm{pg} / \mathrm{mg}$ creatinine); the treatment difference was -0.26 (95\% CI -0.33 to $-0.18) \log \mathrm{pg} / \mathrm{mg}$ creatinine $(\mathrm{p}<0.0001)$. Similarly, the former group had a significant reduction in P-selectin levels as opposed to the placebo group (mean change -0.19 vs $0.041 \log \mathrm{ng} / \mathrm{mL}$ ); the difference between treatments was -0.23 (95\% CI -0.33 to -0.12 ) $\log \mathrm{ng} / \mathrm{mL}$ $(\mathrm{p}<0.0001)$. Also, 8-iso-PGF2 $\alpha$ excretion rate decreased significantly more in the acarbose group (by $33 \%$ vs baseline) than in the placebo group (mean change -0.19 vs $0.013 \log \mathrm{pg} / \mathrm{mg}$ creatinine); the difference between treatments was $-0.20(95 \%$ CI -0.27 to -0.13$)$ $\log \mathrm{pg} / \mathrm{mg}$ creatinine $(\mathrm{p}<0.0001)$. The plasma CD40L also had a median decrease of $31 \%$ versus baseline after 20 weeks of acarbose therapy. ${ }^{45}$

The data demonstrating beneficial effects of acarbose on endothelial dysfunction are somewhat limited. However, Shimabukuro et al observed that acarbose therapy in people with diabetes stopped the postprandial 120 and $240 \mathrm{~min}$ decrease in peak forearm blood flow response and total reactive hyperaemic flow, and the markers of resistance artery endothelial function on strain-gauge plethysmography were no longer seen. Also, these variables had a significant inverse correlation with peak glucose, plasma glucose excursion and $\triangle \mathrm{AUC}$ glucose. However, this study did not compare the longterm effects of acarbose therapy on postprandial endothelial function. ${ }^{43}$ Kato et al evaluated these long-term effects of acarbose therapy for 12 weeks, and concluded that postprandial flow mediated dilation (FMD) of the brachial artery with acarbose therapy was significantly higher $(p<0.05)$ than that with placebo. The percentage of postprandial decrease in FMD from baseline fasting FMD was significantly blunted in the acarbose group as opposed to the control group $(-1.5 \pm 0.95$ vs $-5.0 \pm 2.4 \%$, $\mathrm{p}<0.001){ }^{46} \quad$ On $\quad$ extrapolating postprandial hyperglycaemia-induced pathological changes into animal models, acarbose was shown to prevent intracardiac interstitial fibrosis and cardiomyocytes hypertrophy. ${ }^{47}$

This evidence, when considered in a broad perspective, suggests that postprandial hyperglycaemia is likely to cause vascular homeostatic imbalance and proatherogenic endothelial dysfunction, further increasing CV risk. Acarbose, by reducing postprandial glucotoxicity, may be an effective therapy in reducing these adverse effects.

\section{Kidney function}

Hyperglycaemic states play a key role in kidney dysfunction. This is initiated by genesis of glomerular hyperfiltration, ${ }^{48}$ which is later succeeded by a state that is characteristically referred to as diabetic nephropathy. ${ }^{49}$ This hyperglycaemic damage is known to be worse in patients with existing kidney disease (eg, those having proteinuria as compared to those with normal albumin excretion)..$^{51}$ This hyperglycaemia-induced increase in 
glomerular filtration rate has a brisk onset and persists until high glucose levels return to normal. ${ }^{52}$ Also, glucose excursions have been demonstrated to stimulate increased collagen production by mesangial cells in vitro, which is a key characteristic of diabetic kidney disease. ${ }^{53} 54$

Postprandial hyperglycaemia has been shown to be inversely associated with the time interval between diabetes and the development of nephropathy in people with both type 1 diabetes and T2DM. ${ }^{55}$ Despite this important relationship between glycaemic control and diabetes-induced kidney dysfunction, the effect of acarbose therapy remains less evaluated, especially in human beings. Most evidence is based on findings observed in animal models.

Initial research in the $1980 \mathrm{~s}$ used the $\mathrm{db} / \mathrm{db}$ mouse model to demonstrate the effects of acarbose on renal function. These models were selected as mice develop nephropathy rather quickly (ie, by 3 months of age), which is characterised by endogenous immunoglobulin deposition in the glomerular mesangium and progressive widening of the glomerular mesangial matrix. ${ }^{57}$ This makes them an ideal animal model to evaluate the effects on the kidneys in just a short period of time. Four groups of test animals were tested-controls $(\mathrm{N}=6)$, A-10 $(\mathrm{N}=6$, that received acarbose $10 \mathrm{mg} / 100 \mathrm{~g})$, A-20 $(\mathrm{N}=7$, that received acarbose $20 \mathrm{mg} / 100 \mathrm{~g})$ and $\mathrm{A}-40$ $(\mathrm{N}=6$, that received acarbose $40 \mathrm{mg} / 100 \mathrm{~g})$. It was observed that the control and A-10 group had similar intensity and distribution of immunoglobulin staining (IgG and IgM). The A-20 group had a different pattern as opposed to controls for $\operatorname{IgM}(\mathrm{p}=0.002)$ and $\operatorname{IgA}$ $(\mathrm{p}=0.001)$ staining. Interestingly, the A-40 group had significantly less immunofluorescence staining (distribution and intensity) with each immunoglobulin sample ( $p$ values, $\operatorname{IgM}=0.001, \operatorname{IgA}=0.01, \operatorname{IgG}=0.05$ ) as compared to other groups. Also, unlike the animals in the control group, the animals in this group demonstrated significantly less mesangial area and no evidence of increased mesangial cellularity, and had normal glomerular and tubular basement membranes. ${ }^{58}$ Similarly, in 1990, a comparable research study conducted using Cohen and Rosenmann ${ }^{59}$ diabetic rats demonstrated significantly less incidence and severity of glomerulosclerosis in study animals as compared to controls, with 3 months $(\mathrm{p}<0.05), 5$ and 7 months $(\mathrm{p}<0.01)$ of acarbose therapy. Further research by Cohen et al, ${ }^{60}$ using streptozocin diabetic rats, concluded that 8 weeks of acarbose therapy reduced glomerular basement membrane (GBM) glycation and retarded the nephropathogenic process in experimentally induced diabetes mellitus. Macedo et $a t^{61}$ later made similar conclusions demonstrating that combination therapy with acarbose and insulin in alloxandiabetic rats prevented GBM thickening, and the existing thickening was equivalent to that expected for normal rats of the same age.

Advancing this research, Cohen et a ${ }^{62}$ demonstrated that a similar 8-week course of acarbose therapy after induction of diabetes in streptozocin diabetic rats reduced the increase in urinary albumin excretion (UAE) in untreated diabetic rats with respect to controls. Another investigation from Japan, by Sato et al, revealed that Wistar diabetic rats had a significantly elevated UAE versus non-diabetic controls $(829.0+478.6$ vs $199.1+60.6 \mathrm{pg} /$ day, $\mathrm{p}<0.001$ ), while rats on 8 weeks of acarbose therapy demonstrated UAE suppression versus diabetic rats $(411.7+309.7 \mu \mathrm{g} /$ day, $\mathrm{p}<0.05)$. Also, diabetic rats had elevated, while acarbose treated rats had a significant suppression, of hyperglycaemia-induced increase in creatinine clearance as opposed to nondiabetic controls $(\mathrm{p}<0.05$ for both comparisons). Lastly, acarbose was also shown to normalise the density and number of anionic sites on GBM, which were normally depleted in diabetic rats. ${ }^{63}$

Macedo et al evaluated the effects of long-term treatment with insulin and/or acarbose on GBM thickening in alloxan-diabetic rats. They found that untreated diabetic rats had a significantly thicker GBM as opposed to normal rats. Beginning at 6 months after diabetes induction, the GBM of untreated diabetic rats was significantly $(\mathrm{p}<0.05)$ thicker $(4.446+/-0.45 \mathrm{~mm})$ than that of normal rats $(2.977+/-0.63 \mathrm{~mm})$. Both insulin and acarbose prevented GBM thickening and their combination induced thickening similar to the age-dependent thickening observed for normal rats of the same age. ${ }^{61}$

The possible beneficial effects of acarbose treatment in patients of chronic kidney disease (CKD) were evaluated by Evenepoel et $a l_{.}^{64}$ Patients with CKD and on haemodialysis $(n=107)$, have been shown to possess high concentrations of p-cresol (20.10 (0.30-64.45) $\mathrm{mg} / \mathrm{L})$ and other protein fermentation metabolites. ${ }^{65}$ Also, numerous in-vitro data suggest possible implication of p-cresol in immunodeficiency and endothelial dysfunction, which characterise the uraemic syndrome. ${ }^{66-70}$ The ability of acarbose to increase colonic carbohydrate availability and lower $\mathrm{pH}$ by increasing colonic production of short-chain fatty acid butyrate ${ }^{71-73}$ helps bacteria to use carbohydrates for energy instead of fermenting amino-acids. This process is referred to as "cataboliterepression, ${ }^{74-78}$ This decreases the ammonia and nitrogen load to be filtered by the kidneys, and protects kidney function. Per-protocol analysis by Wilcoxon signed rank test for paired data revealed significant differences between baseline and acarbose treatment, serum p-cresol $(\mathrm{mg} / \mathrm{L})-1.14$ (CI 0.93 to 3.03 ) versus 1.11 (CI 0.31 to 1.82$), \mathrm{p}=0.047$, urinary $\mathrm{p}$-cresol $(\mathrm{mg} /$ day $)$ -29.93 (CI 6.79 to 75.19 ) versus 10.54 (CI 1.08 to $30.85), \mathrm{p}=0.031$, urinary $\mathrm{p}$-cresol/urea nitrogen ratio (mg/g) -1.65 (CI 0.46 to 6.33 ) versus 0.62 (CI 0.05 to 2.38), $\mathrm{p}=0.031$ and faecal nitrogen $(\mathrm{g} /$ day $)-1.04$ (CI 0.47 to 2.29 ) versus 1.99 (CI 0.76 to 3.08 ), $\mathrm{p}=0.047$, respectively. ${ }^{64}$ Additionally, in contrast to other AGIs, acarbose is not absorbed from the intestinal lumen, making it an ideal candidate in patients with CKD. ${ }^{79}{ }^{80}$ Considering the above evidence, acarbose likely has renoprotective effects, particularly in those with, or at 
risk of, diabetes. Further research is warranted to evaluate the use of acarbose on renal function.

\section{Lipaemia}

The beneficial effects of acarbose therapy on serum lipids have been well described. Initial research by Hillebrand $e t a l,{ }^{81}$ from a double-blind crossover study, showed that acarbose has a dose-dependent effect for reducing postprandial total triglycerides, with a $200 \mathrm{mg}$ dose being the most effective.

Baron $e t a l^{82}$ showed that, with acarbose treatment, the mean fasting cholesterol level fell from $214 \pm 19$ to 187 $\pm 15 \mathrm{mg} / \mathrm{dL}, \mathrm{p}<0.03$, the mean high-density lipoprotein (HDL) cholesterol level rose from $41 \pm 4$ to $44 \pm 7 \mathrm{mg} / \mathrm{dL}$, $\mathrm{p}>0.05$, and the HDL to total cholesterol (TC) ratio increased from $0.20 \pm 0.02$ to $0.24 \pm 0.03, \mathrm{p}<0.05$. The triglyceride levels in patients on acarbose were lower throughout the day and the integrated area under the triglyceride concentration curve was $16211 \pm 2875 \mathrm{mg}$ / $\mathrm{dL} / \mathrm{h}$ pretreatment compared to $11127 \pm 1827 \mathrm{mg} / \mathrm{dL} /$ $\mathrm{h}$ post-treatment $(\mathrm{p}<0.05){ }^{82}$

In 1989, Walter-Sack et $a l^{83}$ concluded that, in patients fed with a fibre-free formula diet, acarbose reduced total cholesterol, LDL cholesterol and fasting triglyceride concentration. Reaven $e t a l^{84}$ showed that acarbose lowered plasma triglyceride concentrations $(2.4 \pm 0.1$ to 2.1 $\pm 0.1 \mathrm{mM}, \mathrm{p}<0.01)$ in individuals with poorly controlled T2DM $(\mathrm{n}=12)$.

Hanefeld et $a l^{85}$ demonstrated, in a randomised, double-blind, placebo-controlled trial, that acarbose (100 mg three times daily) for 24 weeks as a first line therapy in patients with T2DM $(\mathrm{n}=94)$ reduced $1 \mathrm{~h}$ postprandial triglyceride levels. Another description by Leonhardt et $a l^{86}$ showed that acarbose reduced total serum cholesterol and total-to-HDL-cholesterol ratio. Also, after a test meal on day 0 and on week 24 of acarbose treatment, there was a significantly lower postprandial rise in serum triglycerides. ${ }^{86}$

Kado $e t a l^{87}$ evaluated the effect of acarbose on postmeal lipaemia, in a crossover, placebo controlled trial involving patients with T2DM treated solely with medical nutrition therapy and/or sulfonylureas. They observed significantly lower serum triglycerides on post-meal tests with and without acarbose at 60, 90 and $120 \mathrm{~min}$ $(\mathrm{p}<0.01, \mathrm{p}<0.01$ and $\mathrm{p}<0.05$, respectively). On measuring serum remnant-like particle (RLP) cholesterol postprandially, with and without acarbose, there were significant differences in favour of acarbose at 60 and $120 \mathrm{~min}$ ( $\mathrm{p}<0.05$ for both) ${ }^{87}$ Plasma RLP cholesterol is known to be involved in pathogenesis of atherosclerosis. ${ }^{88}$ Additionally, the serum apoC-II level at fasting level was significantly lesser than at 30,60, 90, 120 and $180 \mathrm{~min}$ postprandial. $^{87}$

In a randomised placebo controlled study by Ogawa et $a l,{ }^{89}$ using a single dose of $100 \mathrm{mg}$ of acarbose and long-term treatment with $300 \mathrm{mg} /$ day for 8 weeks, it was revealed that both therapies reduced one or more of the following: free fatty acids (FFAs) (postprandial or fasting), postprandial total triglycerides, and very lowdensity lipoprotein and chylomicron (CM) levels. Furthermore, two studies by Derosa et a ${ }^{{ }^{0}}{ }^{91}$ concluded that 7 months of acarbose therapy decreased TC, triglycerides and LDL cholesterol levels as opposed to the control group (both, $\mathrm{p}<0.05$ ). Recently, in another year long prospective, randomised, parallel-group study by Koyasu et $a l,{ }^{92}$ patients on acarbose had a significant decrease from baseline in mean $2 \mathrm{~h}$ fasting TC (from $178.0 \quad(28.3) \mathrm{mg} / \mathrm{dL}$ to $165.5 \quad(22.9) \mathrm{mg} / \mathrm{dL}$; mean change, $-11.26(26.1) \mathrm{mg} / \mathrm{dL} ; \mathrm{p}=0.009)$ and triglyceride concentrations (from $146.8 \quad(79.5) \quad \mathrm{mg} / \mathrm{dL}$ to 112.8 (55.7) $\mathrm{mg} / \mathrm{dL}$; mean change, -30.4 (62.7) $\mathrm{mg} / \mathrm{dL}$; $\mathrm{p}=0.003$ ).

The landmark STOP-NIDDM trial came to similar conclusions on the triglyceride-lowering efficacy of acarbose therapy. The mean change in triglycerides from baseline to 3 years was favourable (placebo, -0.04 vs acarbose, $-0.18 \mathrm{mg} / \mathrm{dL}$ ), and the effect of acarbose evaluated using a repeated measures analysis of variance in reducing triglyceride levels was significant $(p=0.01)$. The evaluation of relationship, according to the Cox Proportional Hazards Model Analysis, between treatment allocation and total triglyceride on the development of cardiovascular events, led to a HR of 1.236 (CI 1.001 to $1.526, \mathrm{p}=0.05$ ). The HRs for total, HDL and LDL cholesterol were 1.146 (CI 0.850 to 1.545 ), 0.382 (CI 0.125 to 1.170 ) and 1.185 (CI 0.838 to 1.677 ), respectively, but were not significant. ${ }^{93}$

The Essen II study $(\mathrm{n}=96)$ in patients with uncontrolled T2DM treated at baseline solely with medical nutrition, compared the therapeutic effects of 24 weeks of acarbose with metformin on the serum lipid profile. There was a $26.8 \%$ decrease in mean triglycerides among the acarbose group, compared to $9.2 \%$ in the metformin group, and an $8.8 \%$ reduction in the placebo group. The LDL-C level increased by $5 \%$ in the placebo group, but was reduced by $21.8 \%$ with acarbose treatment, and remained unchanged with metformin treatment $(\mathrm{p}=0.0065$ for acarbose vs placebo; $\mathrm{p}=0.0134$ for acarbose vs metformin). HDL cholesterol improved by $16.2 \%$ with acarbose treatment, was lowered by $9.7 \%$ in the placebo group and was unaffected by metformin ( $p=0.0162$ for acarbose vs placebo). The LDL-C to HDL-C ratio decreased $26.7 \%$ with acarbose, was unaltered by metformin, and by $14.4 \%$ in the placebo group ( $\mathrm{p}=0.0013$ for acarbose vs placebo; $\mathrm{p}=0.0311$ for acarbose vs metformin).$^{94}$ Another study by Willms and Ruge $^{95}$ showed that acarbose and metformin therapy had similar outcomes regarding TC concentration ( $-0.23 \mathrm{mM}$ for both), but acarbose was superior in triglyceride reduction $(-0.41 \mathrm{mM}$ for acarbose, $-0.27 \mathrm{mM}$ for metformin, and $-0.3 \mathrm{mM}$ for placebo).

A recent meta-analysis evaluating the effects of acarbose, pioglitazone, DPP-4 inhibitors and sulfonylureas showed that triglycerides were reduced significantly with acarbose (MD $-0.19(-0.24$ to -0.15$) \mathrm{mmol} / \mathrm{L} ; 95 \%$ CI -16.81 (-21.23 to -13.27$) \mathrm{mg} / \mathrm{dL}$ ), pioglitazone (MD 
$-0.24(-0.26$ to -0.21$) \mathrm{mmol} / \mathrm{L} ; 95 \%$ CI -20.85 $(-23.01$ to -18.58$) \mathrm{mg} / \mathrm{dL})$ and dipeptidyl peptidase (DPP)-4 inhibitors (MD $-0.19(-0.34$ to -0.05$) \mathrm{mmol} /$ L; $95 \%$ CI $-16.81(-26.55$ to -4.42$) \mathrm{mg} / \mathrm{dL})$, but not with sulfonylureas. HDL cholesterol increased with acarbose and pioglitazone therapy, was reduced by sulfonylureas and remained unchanged with DPP-4 inhibitors. All drugs, except acarbose, resulted in TC reduction (this is likely due to the HDL-raising efficacy of acarbose). ${ }^{96}$

Acarbose has also been shown to be beneficial in other states of hypertriglyceridaemia unrelated to T2DM. In a study involving participants with isolated familial hypertriglyceridaemia, progressive reduction of mean baseline triglyceride levels was demonstrated for 4 months $(\mathrm{p}<0.05)$. There was also an increase in HDL-C with acarbose $(\mathrm{p}<0.008) .{ }^{97}$ Another case report describes use of acarbose for the treatment of severe hypertriglyceridaemia after 10 days of l-asparaginase therapy, along with dexamethasone use, in a patient with acute lymphoblastic leukaemia. Acarbose halved the levels of serum triglycerides in just a few days, and then reduced these levels to less than $10 \mathrm{mmol} / \mathrm{L}^{98}$

A preliminary report by Nakano $e t$ al, which evaluated the mechanism behind the lipid lowering effects of acarbose, used Caco-2 cells, a common in vitro model of enterocytes. On treatment of Caco-2 cells with acarbose $(10 \mathrm{mmol} / \mathrm{L})$, oleic acid absorption decreased by $30 \%$, the amount of secreted triglyceride-rich lipoprotein decreased by around $10 \%$ and apo B-48 secretion reduced by $50 \%$. Apo A-I secretion remained unaffected. ${ }^{99}$ Thus these authors proposed that acarbose could reduce CM synthesis or secretion by intestinal cells, thus decreasing serum lipids. Also, acarbose was shown to reduce apo B-48 secretion, ${ }^{99}$ and thus decrease RLP cholesterol particles, ${ }^{87}$ which is known to be proatherogenic. $^{88}$

Increased levels of non-fasting triglycerides are of even more concern regarding their effect on metabolic health. They lead to increased levels of RLP cholesterol and also predispose to an increased risk of myocardial infarction, ischaemic heart disease and death, in men as well as in women. These conclusions were based on a prospective study by Nordestgaard et al during a mean follow-up of 26 years; 1793 participants (691 women and 1102 men) developed myocardial infarction (MI), 3479 (1567 women and 1912 men) developed IHD and 7818 (3731 women and 4087 men) died. HRs were calculated for four categories of baseline non-fasting triglycerides (TGs) $\quad(1-1.99 \mathrm{mmol} / \mathrm{L} \quad(88.5$ to $176.1 \mathrm{mg} / \mathrm{dL})$, 2$2.99 \mathrm{mmol} / \mathrm{L}(177.0$ to $264.6 \mathrm{mg} / \mathrm{dL}), 3-3.99 \mathrm{mmol} / \mathrm{L}$ $(265.5$ to $353.0 \mathrm{mg} / \mathrm{dL}), \quad 4-4.99 \mathrm{mmol} / \mathrm{L} \quad(354.0$ to $441.6 \mathrm{mg} / \mathrm{dL})$ and $5 \mathrm{mmol} / \mathrm{L}$ or more $(\geq 442.5 \mathrm{mg} / \mathrm{dL}))$ versus TGs of less than $1 \mathrm{mmol} / \mathrm{L}(<88.5 \mathrm{mg} / \mathrm{dL})$. The age-adjusted HRs and multifactorially adjusted HRs (aHRs) for MI in each category were 2.2 (aHR, 1.7), 4.4 (aHR, 2.5), 3.9 (aHR, 2.1), 5.1 (aHR, 2.4) and 16.8 (aHR, 5.4), respectively (for both, $\mathrm{p}$ for trend $<0.001$ ), in women, and 1.6 (aHR, 1.4), 2.3 (aHR, 1.6), 3.6 (aHR, 2.3), 3.3 (aHR, 1.9) and 4.6 (aHR, 2.4), respectively (for both, $\mathrm{p}$ for trend $<0.001$ ), in men. The HR values for IHD were 1.7 (aHR, 1.4), 2.8 (aHR, 1.8), 3.0 (aHR, 1.8), 2.1 (aHR, 1.2) and 5.9 (aHR, 2.6), respectively (for both, $\mathrm{p}$ for trend $<0.001$ ), in women, and 1.3 (aHR, 1.1), 1.7 (aHR, 1.3), 2.1 (aHR, 1.3), 2.0 (aHR, 1.2) and 2.9 (aHR, 1.5), respectively ( $\mathrm{p}$ for trend $<0.001$ for HR and $\mathrm{p}$ for trend=0.03 aHR), in men. Lastly, the ratios for total death, among women, were 1.3 (aHR, 1.3), 1.7 (aHR, 1.6), 2.2 (aHR, 2.2), 2.2 (aHR, 1.9) and 4.3 (aHR, 3.3 ), respectively (for both, $\mathrm{p}$ for trend $<0.001$ ), and 1.3 (aHR, 1.2), 1.4 (aHR, 1.4), 1.7 (aHR, 1.5), 1.8 (aHR, 1.6) and 2.0 (aHR, 1.8), respectively (for both, $\mathrm{p}$ for trend $<0.001$ ), in men. ${ }^{100}$ Thus acarbose, by its advantageous effect on postprandial lipid metabolism may be a useful drug to improve morbidity and mortality outcomes of diabetes (further discussed below).

\section{Gut hormones}

Acarbose is effective in increasing circulating postprandial active GLP-1 (glucagon-like polypeptide-1) levels and aids the action of DPP-4 inhibitors, and simultaneously decreases glucose-dependent insulinotropic polypeptide (GIP). ${ }^{101-103}$ Qualmann et al ${ }^{103}$ concluded that there was an early increment in GLP-1, 15 min after sucrose was fed, however, after acarbose therapy, GLP-1 release was prolonged $(\mathrm{p}<0.0001)$. Enç et $a l^{102}$ demonstrated that acarbose blunted responses of plasma insulin and GIP, while facilitating responses of cholecystokinin, GLP-1 and peptide YY $(\mathrm{p}<0.05-0.001)$. Also, these authors showed that acarbose further potentiates the postprandial reduction of ghrelin, thus suppressing appetite. A recent 24-week study demonstrated that, with acarbose therapy, fasting GLP-1 concentrations increased by $10 \%$ and postprandial GLP-1 by $20 \% \quad(4.92$ $\pm 0.94 \mathrm{pmol} / \mathrm{L}-5.46 \pm 1.28 \mathrm{pmol} / \mathrm{L}$ and $5.23 \pm 1.26 \mathrm{pmol} /$ $\mathrm{L}-6.26 \pm 1.64 \mathrm{pmol} / \mathrm{L}$, respectively; for both $\mathrm{p}<0.05) .{ }^{101}$

The increased production of GLP-1 potentiates the pancreatic $\beta$ cell mediated insulin secretion and also reverses pancreatic cell glucolipotoxicity as a direct effect. ${ }^{104-108}$ This chronic GLP-1 upregulation may add to acarbose's effect of postprandial hyperglycaemia reduction, and thus benefit those with diabetes.

GLP-1 is known to have a direct effect on vascular endothelium and thus facilitate eNOS (epithelial nitrous oxide synthase) activity. ${ }^{109-111}$ In the study above, GLP-1 levels varied linearly with NO and NOS levels. ${ }^{101}$ The activation of AMPK also adds to GLP-1's positive influence on the endothelium. ${ }^{112}$ GLP-1 reduces hepatic fatty acid synthesis, increases their oxidation, ${ }^{113} 114$ and GLP-1 agonists have been demonstrated to have favourable effects on rodent models and in humans with nonalcoholic fatty liver disease, however, this requires further evaluation. ${ }^{109}$ 115-119 Additionally, a number of studies have shown that pretreatment with long-acting GLP-1 agonists helps to reduce the impact of ischaemic reperfusion injury on the heart. ${ }^{120-124}$ It was seen that 
this synergistic effect was removed with concurrent administration of inhibitors of mitochondrial ATP-sensitive $\mathrm{K}$ channels (mKATP). ${ }^{124}$ Conversely, ischaemic preconditioning involves upregulation of mKATP channels, thus preventing ischaemic-reperfusion injury. ${ }^{125}$ The channels open during ischaemic injury and reduce the potential gradient, thus decreasing mitochondrial calcium influx, and, in turn, preserving mitochondrial function. ${ }^{114}{ }^{126}$ This suggests that acarbose may exert a protective effect on the heart mechanistically similar to ischaemic preconditioning and may reduce infarct size. ${ }^{127}$ Acarbose has also been shown to be beneficial in patients with Roux-en-Y Gastric Bypass operations as it ameliorates reactive hypoglycaemia. ${ }^{128} 129$

\section{PATIENT-RELATED OUTCOMES Weight loss}

Consistent data demonstrate that acarbose induces weight loss in animals. ${ }^{130}$ The data in humans are more ambiguous; some reports indicate that acarbose is weight-neutral, ${ }^{85} 131132$ while others report significant weight loss. The studies reporting weight loss are mostly from Asia, and some of them report weight loss of more than $1 \mathrm{~kg} .{ }^{133} 134$ The explanation for the weight-loss effect of acarbose has been attributed to its ability to increase secretion of GLP-1. ${ }^{101}$

A recent ethno-specific meta-analysis by Li et al evaluated the effects of acarbose monotherapy on weight in Eastern and Western populations. Overall, acarbose was shown to provide significantly more weight-loss by an average of $0.52 \mathrm{~kg}(95 \% \mathrm{CI}-0.78$ to -0.25$)$ as opposed to placebo $(\mathrm{p}=0.0001)$, and, in the Eastern population, acarbose caused significant weight loss of $1.20 \mathrm{~kg}(95 \%$ CI -1.73 to -0.68$)$ compared with placebo $(\mathrm{p}<0.05)$, whereas in the Western group, it produced minimal, insignificant weight loss of $0.28 \mathrm{~kg}(95 \%$ CI -0.59 to $0.03)$ versus placebo $(p=0.08)$. Also, it was found that acarbose was more effective for weight reduction in the Eastern compared to Western population (by $0.92 \mathrm{~kg}$, $\left.\chi 2=8.91, \mathrm{df}=1, \mathrm{p}<0.05 ; \mathrm{I}^{2}=88.8 \%\right)$. Additionally, acarbose lowered overall body mass index (BMI) by $0.55 \mathrm{~kg} / \mathrm{m}^{2}$ (95\% CI -0.86 to $-0.23, \mathrm{p}<0.05)$, however, no significant population-based differences were observed. On comparison with nateglinide, acarbose was shown to provide significantly greater weight loss by $1.13 \mathrm{~kg}(95 \%$ CI -1.51 to -0.75$)$, with $-1.40 \mathrm{~kg}$ (95\% CI -1.88 to -0.91$)$ for Eastern populations versus $-0.68 \mathrm{~kg}$ (95\% CI -1.30 to -0.06 ) for Western populations. Acarbose was also shown to be superior to metformin with a further $0.67 \mathrm{~kg}$ weight reduction (95\% CI -1.14 to -0.20$)$. This difference was more pronounced and significant in the Eastern compared to Western population $(-0.67,95 \%$ CI -1.14 to -0.20 and $-0.30,95 \%$ CI -5.45 to 4.85 , respectively). The absolute reductions for Eastern populations and Western populations, respectively, in body weight with acarbose therapy (as compared to baseline) were $2.26 \mathrm{~kg}(95 \% \mathrm{CI}-2.70$ to -1.81$)$ and $0.91 \mathrm{~kg}(95 \%$ CI -1.36 to -0.47 ), with a significant trend towards the former (difference: $-1.35 \mathrm{~kg} ; \chi^{2}=17.55, \mathrm{df}=1, \mathrm{p}<0.05$; $\mathrm{I}^{2}=94.3 \%$ ). Also, reduction in absolute BMI with acarbose therapy was $1.68 \mathrm{~kg} / \mathrm{m}^{2} \quad(-3.37$ to 0.02$)$ and $0.45 \mathrm{~kg} / \mathrm{m}^{2}$ (-0.82 to -0.08$)$ for Eastern populations and Western populations, respectively; however, the inter-group difference was non-significant. ${ }^{135}$

It has been reported that each $1 \mathrm{~kg}$ of weight reduction improves life expectancy by 3-4 months in individuals with diabetes. ${ }^{136}$ Also, Wing et $a l^{137}$ have concluded that modest weight loss of $5-10 \%$ leads to a significant improvement in CVD risk factors at 1 year. These benefits were increased with larger weight reduction. Thus, acarbose may be useful as an adjunct to diet and exercise for reducing cardiovascular risk and improving longevity in hyperglycaemic individuals.

\section{CARDIOVASCULAR RISK}

Glucose excursions are known to be key mediators of macrovascular and microvascular complications, not only in diabetic individuals but also in people with impaired glucose tolerance (IGT).$^{9}$ Persons with IGT are almost three-times more likely to develop coronary heart disease and other major cardiovascular events than people with normal glucose tolerance (NGT) ${ }^{10}$ Acarbose, by benefitting the surrogate markers of CVD (as described above), may be a useful drug for reducing CVD risk (box 1).

The landmark Study to Prevent Non-InsulinDependent Diabetes Mellitus (STOP-NIDDM) trial evaluated the utility of acarbose therapy over 3 years versus placebo for the prevention of diabetes among 1429 patients with IGT. In the patients randomised to acarbose therapy, 32\% developed overt diabetes compared to $42 \%$ on placebo (relative hazard 0.75 (95\% CI 0.63 to 0.90$) ; \mathrm{p}=0.0015)$. Additionally, acarbose significantly reversed IGT to NGT; an effect that was highly significant when compared to the placebo group $(p<0.0001)$. Importantly, acarbose also led to a $49 \%$

\section{Box 1 Effects of acarbose on surrogate markers of CVD}

Reduces postprandial hyperglycaemia and glucose excursions

- Minimises reactive hypoglycaemia

- Improves release of GLP-1

- Inhibits platelet activation

- Protects kidney function

- Has positive effects on lipid profile-increasing HDL cholesterol, decreasing fasting and non-fasting TGs, and LDL cholesterol

- Improves vascular health-increases eNOS activity and NO concentrations, reduces oxidative stress and prevents endothelial dysfunction

Promotes weight loss, especially among Eastern populations

Improves blood pressure and decreases risk hypertension.

CVD, cardiovascular disease; eNOS, epithelial nitrous oxide synthase; GLP-1, glucagon-like peptide 1; HDL, high-density lipoprotein; LDL, low-density lipoprotein; 
relative risk reduction (2.5\% absolute risk reduction) in cardiovascular (CV) events (HR: $0.51 ; 95 \%$ CI 0.28 to $0.95 ; \mathrm{p}=0.03$ ) with a $91 \%$ relative risk reduction in the risk of MI (HR, $0.09 ; 95 \%$ CI 0.01 to $0.72 ; \mathrm{p}=0.02)$ and a $34 \%$ relative risk reduction (a $5.3 \%$ absolute risk reduction) in the incidence of newly diagnosed hypertension (HR, 0.66 ; $95 \%$ CI 0.49 to $0.89 ; \mathrm{p}=0.006$ ). The cardiovascular event risk reduction ( $\mathrm{HR}, 0.47 ; 95 \%$ CI 0.24 to $0.90 ; \mathrm{p}=0.02$ ) and hypertension risk reduction (HR, $0.62 ; 95 \%$ CI 0.45 to $0.86 ; \mathrm{p}=0.004)$ linked with acarbose treatment remained statistically significant even after adjusting for major risk factors. ${ }^{93} 138$

MeRia (MEta-analysis of Risk Improvement under Acarbose), a meta-analysis of seven randomised trials testing acarbose in 2180 patients with T2DM and a follow-up of 1 year or longer, revealed a significant $64 \%$ decrease of relative risk of myocardial infarction (9 vs $19, \mathrm{HR}=0.36(95 \% \mathrm{Cl} 0.16$ to 0.80$), \mathrm{p}=0.0120)$ and $\mathrm{a}$ $35 \%$ relative risk reduction for any CV event (76 vs 88 , $\mathrm{HR}=0.65(95 \% \mathrm{Cl} 0.48$ to 0.88$), \mathrm{p}=0.0061)$ with acarbose therapy versus placebo. ${ }^{139}$ Box 2 summarises the CV benefits of acarbose.

Though it is reasonable to hypothesise that acarbose is beneficial at reducing $\mathrm{CV}$ events, the number of $\mathrm{CV}$ events reported in these studies was small and the dates were obtained from post hoc analyses. Thus, a definitive large, prospective, randomised, placebo controlled trial is warranted to effectively prove the above hypothesis. ${ }^{93} 139140$ To fulfil this requirement, the Acarbose Cardiovascular Evaluation (ACE) Trial was started in 2009, and was designed to assess the usefulness of acarbose in reducing $\mathrm{CV}$ complications in a secondary prevention population with IGT. ${ }^{140} 141$

The ACE trial is a randomised, placebo-controlled, double-blind, secondary prevention trial enrolling 7500 patients with IGT and coronary heart disease (a MI in the past, unstable angina or current stable angina) in

\section{Box 2 Effect of acarbose on CVD outcomes}

- In the Study to Prevent Non-Insulin-Dependent Diabetes Mellitus (STOP-NIDDM) trial, acarbose vs placebo significantly reduced the development of overt diabetes (relative hazard $0.75(95 \% \mathrm{Cl} 0.63$ to 0.90$) ; \mathrm{p}=0.0015)$, IGT to NGT $(p<0.0001)$, CV events (HR: $0.51 ; 95 \% \mathrm{Cl} 0.28$ to 0.95 ; $\mathrm{p}=0.03$ ), $\mathrm{MI}$ (HR, $0.09 ; 95 \% \mathrm{Cl} 0.01$ to $0.72 ; \mathrm{p}=0.02$ ) and incidence of newly diagnosed hypertension ( $\mathrm{HR}, 0.66 ; 95 \% \mathrm{Cl}$ 0.49 to $0.89 ; p=0.006)$. The cardiovascular event risk reduction ( $\mathrm{HR}, 0.47 ; 95 \% \mathrm{Cl} 0.24$ to $0.90 ; \mathrm{p}=0.02$ ) and hypertension risk reduction $(\mathrm{HR}, 0.62 ; 95 \% \mathrm{Cl} 0.45$ to $0.86 ; \mathrm{p}=0.004)$ linked with acarbose treatment remained statistically significant even after adjusting for major risk factors. ${ }^{93} 138$

- A meta-analysis of seven randomised trials in 2180 patients with T2DM, revealed a significant $64 \%$ decrease of relative risk of myocardial infarction (9 vs 19, HR=0.36 (95\% Cl 0.16 to 0.80$), p=0.0120)$ and a $35 \%$ relative risk reduction for any CV event (76 vs 88, HR=0.65 (95\% Cl 0.48 to 0.88$)$, $\mathrm{p}=0.0061)$ with acarbose therapy vs placebo. ${ }^{139}$

CVD, cardiovascular disease; T2DM, type 2 diabetes mellitus.
China and Hong Kong. The patients are randomised into two groups, one receiving acarbose $50 \mathrm{mg}$ three times a day and the other receiving matching placebo in a 1:1 fashion. All the patients will receive effective guideline-based CV care with a minimum of 3 months out from a previous MI. The time to first occurrence of CV death, non-fatal MI or stroke is the primary CV outcome, with the prevention of diabetes as well as allcause mortality as secondary outcomes. ${ }^{140} 141$

\section{Longevity}

With increasing data demonstrating benefits of acarbose therapy in hyperglycaemic individuals, it is reasonable to hypothesise a broader potential of acarbose in health promotion. In a study involving mice spanning their entire lives, it was revealed that an add-on of $0.1 \%$ acarbose to standard diet (65\% carbohydrates and $22 \%$ protein for total caloric intake), starting at the age of 4 months, caused a significant increase in median and maximal lifespan in both sexes, more so in males than females $(22 \%, \mathrm{p}<0.0001$ vs $5 \%, \mathrm{p}=0.01)$. The levels of HbAlc remained uninfluenced because of minimal impact on fasting hyperglycaemia, whereas acarbose mainly impacted the postprandial glucose rise. $^{142}$ However, despite these findings, it is difficult to explain the increase in longevity as these mice were not diabetic and were not at risk of developing diabetes.

It was discovered that acarbose therapy in mice led to a significant rise in the levels of serum FGF21 and a significant decline in serum insulin-like growth factor-1 (IGF-1) levels. ${ }^{142}$ It has been established that systemic IGF-1 activity mediates the ageing process and influences longevity in mice. ${ }^{143}$ Also, FGF 21 by decreasing IGF-1 production decreases the sensitivity of the liver to growth hormone. ${ }^{144-146}$ Moreover, genetically altered mice with constitutive FGF21 secretion have been reported to have increase in both mean and maximal lifespan, thought to be mediated by IGF-1 downregulation. ${ }^{147} 148$

Though there is no evidence of acarbose-induced hepatic FGF21 production, long-term therapy with acarbose diverts surplus glucose to distal parts of the intestine and stimulates GLP-1 production ${ }^{101-103}{ }^{149}$; moreover, long-acting GLP-1 agonists have been reported to stimulate hepatic FGF21 production. ${ }^{146} 150$ The transcription of FGF21 is stimulated after a key interaction between Sirt1 deactylated peroxisome proliferator-activated receptor (PPAR) $\alpha$ with the FGF21 promoter. ${ }^{151-155}$ GLP-1 agonists, by the virtue of increasing PPAR $\alpha$ and Sirt1 expression in hepatocytes, mediate FGF21 upregulation. ${ }^{109} 114156$ Hence, the above statements suggest that acarbose therapy-induced GLP-1 upregulation may promote hepatic FGF21 production, which suppresses IGF-1 activity and thus increases longevity.

\section{SIDE EFFECTS}

Based on more than 20 years of clinical use of acarbose, numerous controlled trials and postmarketing 
surveillance studies have not demonstrated any significant toxicity or possible relation with subsequent comorbidities $^{11}$; however; nuisance-like gastrointestinal side effects can limit its use.

The predominant gastrointestinal symptom associated with acarbose is flatulence; though loose stools and/or abdominal discomfort have also been reported. These result from undigested carbohydrates entering from the small intestine directly into the colon, mimicking malabsorption. The end result is fermentation of this undigested carbohydrate by colonic bacteria leading to intestinal gas production. The incidence of such side effects varies widely over the existing literature. Flatulence and/or meteorism ranges between less than $10 \%$ to more than $50 \%$ of patients on acarbose therapy in controlled trials. Trials in the US report a higher incidence of these symptoms (about 40\%) than in trials from Germany (about 25\%) and Asian trials (about $17 \%) .{ }^{157}$

Surveillance studies evaluating individualised monotherapy, with a better patient-centric approach, form a reliable basis for assessing the intestinal side effects of acarbose. The PROTECT (Precose Resolution of Optimal Titration to Enhance Current Therapies) surveillance study of 6142 patients from the US population, reported the incidence of flatulence to be $37 \% .^{158}$ Another surveillance study, involving 27803 patients from Germany treated with fixed increasing dosages of acarbose, demonstrated a $13.7 \%$ incidence of flatulence. ${ }^{159}$ The reported incidence in German population was even lower $(3.9 \%)$ in a 5-year postmarketing surveillance study $(\mathrm{n}=1996)$ with no fixed acarbose dosing. ${ }^{160}$ Such studies in Chinese and Asian populations showed an incidence of $0.6 \% \quad(n=2550)$ and $2 \% \quad(n=14418)$, respectively. ${ }^{161} 162$

This inter-regional variability may be due to several reasons. Though these side effects were labelled dosedependent by dose-ranging studies, ${ }^{163} 164$ they failed to demonstrate significant efficacy differences between 100 and $50 \mathrm{mg}$ acarbose administered three times daily. Interestingly, most patients in the German ${ }^{160}$ and Asian $^{161}$ studies were treated with acarbose $50 \mathrm{mg}$ three times daily. However, an early study effectively showed $50 \mathrm{mg}$ acarbose to have less malabsorptive side effects as opposed to a $100 \mathrm{mg}$ dose (6\% vs $30 \%) .{ }^{165}$ Another study, by May et $a l^{166}$ assessed the tolerability with a step-by-step increase beginning with a $100 \mathrm{mg}$ dose three times daily, and concluded that gastrointestinal symptoms were reduced from $70 \%$ to $31 \%$ over an 8 week period. Even though controlled studies demonstrate $200 \mathrm{mg}$ three times daily to be more effective, usually, acarbose is prescribed at a maximum of $100 \mathrm{mg}$ three times daily, as the former is known to have a higher incidence of malabsorptive adverse effects. ${ }^{11}$

Another key reason for variance in gastrointestinal symptoms is variability in $\alpha$-glucosidase enzyme activity among populations, due to dietary habits. A study by Creutzfeldt et al evaluating sucrase and maltase (the key $\alpha$-glucosidase enzymes) content in proximal and distal portions of the intestine, revealed that the latter had poor enzyme activity with a fibre-free diet as opposed to with a fibre-rich diet, moving unabsorbed carbohydrates into the colon. It was also observed that the addition of acarbose in participants on a fibre-free diet gradually increased distal intestinal enzyme activity and normalised carbohydrate digestion. However, in the fibre-rich group, the already increased enzyme activity remained unchanged with addition of acarbose. ${ }^{167}$ These data might be a plausible explanation for the populationbased side effect heterogeneity, as the conventional Asian and Chinese diet contains much more fibre as compared to the conventional Western diet. Also, it explains the increased incidence of gastrointestinal symptoms when acarbose therapy is initiated, which eventually dissipate.

Another study emphasising the importance of dietary habits with acarbose use, reported 200 times higher malabsorption with sucrose consumption as opposed to starch, measured by breath hydrogen. Additionally, it suggested increased incidence of gastrointestinal symptoms with sugar rich soft drink consumption. ${ }^{168}$ Thus, rational use, slow titration from low to medium dose, focused patient education and good dietary advice may help ameliorate the gastrointestinal adverse effects associated with acarbose.

Apart from its gastrointestinal effects, acarbose is an extremely safe drug, which is consistent with its site of action and its very low systemic availability. ${ }^{169}{ }^{170}$ A prospective 5-year postmarketing surveillance study $(n=1996)$ reported no severe or fatal adverse events associated with acarbose. ${ }^{160}$ Additionally, the data from STOP-NIDDM trial revealed that incidence of adverse effects with acarbose was similar to that with placebo and no serious adverse events were reported. ${ }^{138}$

Some rare reports, immediately after approval of acarbose, documented elevated liver transaminases with acarbose use ${ }^{171}$; however, no differences were observed in clinical studies as opposed to placebo, and only 19 cases were reported of 500000 participants. ${ }^{172}$ Such transaminasaemia has not been observed during treatment in patients with IGT; moreover, several studies involving acarbose use in diabetic participants demonstrated a beneficial effect on the progression of chronic liver disease. $^{173-175}$

Some labelled contraindications of acarbose include inflammatory bowel disease, colonic ulceration, predisposition or partial intestinal obstruction and chronic malabsorptive disorders. Hypoglycaemia should not occur with acarbose monotherapy in either fasting or postprandial conditions; however, in combination therapy with sulfonylureas or insulin, acarbose may contribute to hypoglycaemia. ${ }^{176}$

Hence, acarbose, when carefully prescribed in combination with adequate dietary advice, seems to be one of the safest antidiabetic agents available, used either alone or in combination with other glucose-lowering 
strategies. However, further randomised controlled trials are required to better understand the safety and efficacy of the AGIs.

\section{CONCLUSION}

Acarbose, an oral AGI, appears to reduce risk of cardiovascular events with a minimal risk for hypoglycaemia. If started at a low dose and titrated slowly, acarbose tends to cause occasional nuisance gastrointestinal side effects that are generally tolerable. Acarbose, as with metformin, should be considered a first-line antidiabetic agent, and is an effective pharmacological option for preventing diabetes in the prediabetic patient. Larger, longterm trials testing acarbose in diabetic patients as well as in other patient populations would be useful to confirm its cardiovascular benefits and safety profile.

Competing interests None declared.

Provenance and peer review Not commissioned; externally peer reviewed.

Data sharing statement No additional data are available.

Open Access This is an Open Access article distributed in accordance with the Creative Commons Attribution Non Commercial (CC BY-NC 4.0) license, which permits others to distribute, remix, adapt, build upon this work noncommercially, and license their derivative works on different terms, provided the original work is properly cited and the use is non-commercial. See: http:// creativecommons.org/licenses/by-nc/4.0/

\section{REFERENCES}

1. Derosa G, Maffioli P. $\alpha$-Glucosidase inhibitors and their use in clinical practice. Arch Med Sci 2012;8:899-906.

2. Puls W. Pharmacology of glucosidase inhibitors. In: Kuhlmann J, Puls W, eds. Oral antidiabetics. Springer, 1996:497-534.

3. Krause $\mathrm{H}$, Ahr $\mathrm{H}$. Pharmacokinetics and metabolism of glucosidase inhibitors. In: Kuhlmann J, Puls W, eds. Oral antidiabetics. Springer, 1996:541-55.

4. Gross LS, Li L, Ford ES, et al. Increased consumption of refined carbohydrates and the epidemic of type 2 diabetes in the United States: an ecologic assessment. Am J Clin Nutr 2004;79:774-9.

5. Dinicolantonio JJ. The cardiometabolic consequences of replacing saturated fats with carbohydrates or $\Omega-6$ polyunsaturated fats: do the dietary guidelines have it wrong? Open Heart 2014;1: e000032.

6. Hanefeld M, Schaper F, Koehler C. Effect of acarbose on vascular disease in patients with abnormal glucose tolerance. Cardiovasc Drugs Ther 2008;22:225-3.

7. Puls W, Keup U, Krause HP, et al. Glucosidase inhibition. Naturwissenschaften 1977;64:536-7.

8. Ferey-Roux G, Perrier J, Forest E, et al. The human pancreatic alpha-amylase isoforms: isolation, structural studies and kinetics of inhibition by acarbose. Biochim Biophys Acta 1998;1388:10-20.

9. Heine RJ, Balkau B, Ceriello A, et al. What does postprandial hyperglycaemia mean? Diabet Med 2004;21:208-13.

10. Standl E, Schnell O, Ceriello A. Postprandial hyperglycemia and glycemic variability: should we care? Diabetes Care 2011;34(Suppl 2):S120-127.

11. Van De Laar FA, Lucassen PL, Akkermans RP, et al. Alpha-glucosidase inhibitors for patients with type 2 diabetes: results from a Cochrane systematic review and meta-analysis. Diabetes Care 2005;28:154-63.

12. Chen HL, Sheu WH, Tai TS, et al. Konjac supplement alleviated hypercholesterolemia and hyperglycemia in type 2 diabetic subjects -a randomized double-blind trial. J Am Coll Nutr 2003:22:36-42.

13. Chearskul S, Sangurai S, Nitiyanant W, et al. Glycemic and lipid responses to glucomannan in Thais with type 2 diabetes mellitus. J Med Assoc Thai 2007:90:2150-7.

14. Celleno L, Tolaini MV, D'amore A, et al. A Dietary supplement containing standardized Phaseolus vulgaris extract influences body composition of overweight men and women. Int $\mathrm{J}$ Med Sci 2007;4:45-52
15. Udani JK, Singh BB, Barrett ML, et al. Lowering the glycemic index of white bread using a white bean extract. Nutr J 2009;8:52.

16. Preuss HG. Bean amylase inhibitor and other carbohydrate absorption blockers: effects on diabesity and general health. J Am Coll Nutr 2009;28:266-76.

17. Barrett ML, Udani JK. A proprietary alpha-amylase inhibitor from white bean (Phaseolus vulgaris): a review of clinical studies on weight loss and glycemic control. Nutr J 2011;10:24.

18. Doi K. Effect of konjac fibre (glucomannan) on glucose and lipids. Eur J Clin Nutr 1995;49(Suppl 3):S190-197.

19. Bogoch S, Bogoch ES. Disarmed anti-malignin antibody in human cancer. Lancet 1979;1:987.

20. Vuksan V, Jenkins DJ, Spadafora $P$, et al. Konjac-mannan (glucomannan) improves glycemia and other associated risk factors for coronary heart disease in type 2 diabetes. A randomized controlled metabolic trial. Diabetes Care 1999;22: 913-19.

21. O'keefe JH, Bell DS. Postprandial hyperglycemia/hyperlipidemia (postprandial dysmetabolism) is a cardiovascular risk factor. Am J Cardiol 2007;100:899-904.

22. O'keefe JH, Gheewala NM, O'keefe JO. Dietary strategies for improving post-prandial glucose, lipids, inflammation, and cardiovascular health. J Am Coll Cardiol 2008;51:249-55.

23. Kim JW, Yoon KH. Glucolipotoxicity in Pancreatic $\beta$-Cells. Diabetes Metab J 2011;35:444-50.

24. Wachters-Hagedoorn RE, Priebe MG, Heimweg JA, et al. Low-dose acarbose does not delay digestion of starch but reduces its bioavailability. Diabet Med 2007;24:600-6.

25. Zhu Q, Tong $\mathrm{Y}, \mathrm{Wu} \mathrm{T}$, et al. Comparison of the hypoglycemic effect of acarbose monotherapy in patients with type 2 diabetes mellitus consuming an Eastern or Western diet: a systematic meta-analysis. Clin Ther 2013;35:880-99.

26. Holman RR, Cull CA, Turner RC. A randomized double-blind trial of acarbose in type 2 diabetes shows improved glycemic control over 3 years (U.K. Prospective Diabetes Study 44). Diabetes Care 1999;22:960-4.

27. Brownlee M. Biochemistry and molecular cell biology of diabetic complications. Nature 2001;414:813-20.

28. Ceriello A, Giugliano D, Quatraro A, et al. Metabolic control may influence the increased superoxide generation in diabetic serum. Diabet Med 1991;8:540-2.

29. Du XL, Edelstein D, Rossetti L, et al. Hyperglycemia-induced mitochondrial superoxide overproduction activates the hexosamine pathway and induces plasminogen activator inhibitor-1 expression by increasing Sp1 glycosylation. Proc Natl Acad Sci U S A 2000;97:12222-6.

30. Nishikawa T, Edelstein D, Du XL, et al. Normalizing mitochondrial superoxide production blocks three pathways of hyperglycaemic damage. Nature 2000;404:787-90.

31. Marfella R, Quagliaro L, Nappo F, et al. Acute hyperglycemia induces an oxidative stress in healthy subjects. J Clin Invest 2001;108:635-6.

32. Ceriello A, Bortolotti N, Crescentini A et al. Antioxidant defences are reduced during the oral glucose tolerance test in normal and non-insulin-dependent diabetic subjects. Eur J Clin Invest 1998;28:329-33.

33. Ceriello A, Quagliaro L, Catone B, et al. Role of hyperglycemia in nitrotyrosine postprandial generation. Diabetes Care 2002;25:1439-43.

34. Kawano $\mathrm{H}$, Motoyama $\mathrm{T}$, Hirashima $\mathrm{O}$, et al. Hyperglycemia rapidly suppresses flow-mediated endothelium-dependent vasodilation of brachial artery. J Am Coll Cardiol 1999;34:146-54.

35. Hanefeld M, Koehler C, Schaper F, et al. Postprandial plasma glucose is an independent risk factor for increased carotid intima-media thickness in non-diabetic individuals. Atherosclerosis 1999;144:229-35.

36. Bonora E, Kiechl S, Oberhollenzer F, et al. Impaired glucose tolerance, Type II diabetes mellitus and carotid atherosclerosis: prospective results from the Bruneck Study. Diabetologia 2000;43:156-64.

37. Temelkova-Kurktschiev TS, Koehler C, Henkel E, et al. Postchallenge plasma glucose and glycemic spikes are more strongly associated with atherosclerosis than fasting glucose or HbA1c level. Diabetes Care 2000;23:1830-4.

38. Hanefeld M, Chiasson JL, Koehler C, et al. Acarbose slows progression of intima-media thickness of the carotid arteries in subjects with impaired glucose tolerance. Stroke 2004;35: 1073-8.

39. Ludwig M, Kraft K, Rucker W, et al. [Diagnosis of very early arteriosclerosis vascular changes using Duplex sonography]. Klin Wochenschr 1989;67:442-6. 
40. Esposito K, Nappo F, Marfella R, et al. Inflammatory cytokine concentrations are acutely increased by hyperglycemia in humans: role of oxidative stress. Circulation 2002;106:2067-72.

41. Ceriello A, Falleti E, Motz E, et al. Hyperglycemia-induced circulating ICAM-1 increase in diabetes mellitus: the possible role of oxidative stress. Horm Metab Res 1998;30:146-9.

42. Marfella R, Esposito K, Giunta R, et al. Circulating adhesion molecules in humans: role of hyperglycemia and hyperinsulinemia. Circulation 2000;101:2247-51.

43. Shimabukuro M, Higa N, Chinen I, et al. Effects of a single administration of acarbose on postprandial glucose excursion and endothelial dysfunction in type 2 diabetic patients: a randomized crossover study. J Clin Endocrinol Metab 2006;91:837-42.

44. Wascher TC, Schmoelzer I, Wiegratz A, et al. Reduction of postchallenge hyperglycaemia prevents acute endothelial dysfunction in subjects with impaired glucose tolerance. Eur J Clin Invest 2005;35:551-7.

45. Santilli F, Formoso G, Sbraccia P, et al. Postprandial hyperglycemia is a determinant of platelet activation in early type 2 diabetes mellitus. J Thromb Haemost 2010;8:828-37.

46. Kato T, Inoue T, Node K. Postprandial endothelial dysfunction in subjects with new-onset type 2 diabetes: an acarbose and nateglinide comparative study. Cardiovasc Diabetol 2010:9:12.

47. Miyamura M, Schnell O, Yamashita $\mathrm{C}$, et al. Effects of acarbose on the acceleration of postprandial hyperglycemia-induced pathological changes induced by intermittent hypoxia in lean mice. $J$ Pharmacol Sci 2010;114:32-40.

48. Skott P, Vaag A, Hother-Nielsen O, et al. Effects of hyperglycaemia on kidney function, atrial natriuretic factor and plasma renin in patients with insulin-dependent diabetes mellitus. Scand J Clin Lab Invest 1991;51:715-27.

49. Wiseman MJ, Saunders AJ, Keen $\mathrm{H}$, et al. Effect of blood glucose control on increased glomerular filtration rate and kidney size in insulin-dependent diabetes. N Engl J Med 1985;312:617-21.

50. Remuzzi A, Viberti G, Ruggenenti P, et al. Glomerular response to hyperglycemia in human diabetic nephropathy. Am J Physiol 1990;259(4 Pt 2):F545-552.

51. Tuttle KR, Bruton JL, Perusek MC, et al. Effect of strict glycemic control on renal hemodynamic response to amino acids and renal enlargement in insulin-dependent diabetes mellitus. N Engl J Med 1991;324:1626-32.

52. De Cosmo S, Earle K, Morocutti A, et al. Glucose-induced changes in renal haemodynamics in proteinuric type 1 (insulin-dependent) diabetic patients: inhibition by acetylsalicilic acid infusion. Diabetologia 1993;36:622-7.

53. Steffes MW, Bilous RW, Sutherland DE, et al. Cell and matrix components of the glomerular mesangium in type I diabetes. Diabetes 1992;41:679-84.

54. Takeuchi A, Throckmorton DC, Brogden AP, et al. Periodic high extracellular glucose enhances production of collagens III and IV by mesangial cells. Am J Physiol 1995;268(1 Pt 2):F13-19.

55. Shichiri M, Kishikawa $\mathrm{H}$, Ohkubo $\mathrm{Y}$, et al. Long-term results of the Kumamoto Study on optimal diabetes control in type 2 diabetic patients. Diabetes Care 2000;23(Suppl 2):B21-29.

56. Hasslacher C, Ritz E. Effect of control of diabetes mellitus on progression of renal failure. Kidney Int Suppl 1987;22:S53-6.

57. Lee SM, Graham A. Early immunopathologic events in experimental diabetic nephropathy: a study in db/db mice. Exp Mol Pathol 1980;33:323-32.

58. Lee SM. The effect of chronic $\alpha$-glycosidase inhibition on diabetic nephropathy in the $\mathrm{db} / \mathrm{db}$ mouse. Diabetes 1982;31:249-54.

59. Cohen AM, Rosenmann E. Acarbose treatment and diabetic nephropathy in the Cohen diabetic rat. Horm Metab Res 1990;22:511-15.

60. Cohen MP, Klepser H, Wu VY. Effect of alpha-glucosidase inhibition on the nonenzymatic glycation of glomerular basement membrane. Gen Pharmacol 1991;22:515-19.

61. Macedo CS, Silva MD, Spadella CT, et al. Effect of long-term treatment with insulin and/or acarbose on glomerular basement membrane thickening in alloxan-diabetic rats. Braz J Med Biol Res 1996;29:1329-35.

62. Cohen MP, Vasselli JR, Glenn Neuman R, et al. Treatment with acarbose, an $\alpha$-glucosidase inhibitor, reduces increased albumin excretion in streptozotocin-diabetic rats. Gen Pharmacol 1995;26:1355-61.

63. Sato $H$, Shiina $N$. Effect of an $\alpha$-glucosidase inhibitor on glomerular basement membrane anionic sites in streptozotocin induced mildly diabetic rats. Diabetes Res Clin Pract 1997;37:91-9.

64. Evenepoel P, Bammens B, Verbeke K, et al. Acarbose treatment lowers generation and serum concentrations of the protein-bound solute p-cresol: a pilot study. Kidney Int 2006;70:192-8.
65. Vanholder R, De Smet R, Glorieux R. Review on uremic toxins: classification, concentration, and interindividual variability. Kidney Int 2003;63:1934-43.

66. Wratten ML, Tetta $C$, De Smet R. Uremic ultrafiltrate inhibits platelet-activating factor synthesis. Blood Purif 1999;17:134-41.

67. Vanholder R, De Smet R, Waterloos MA. Mechanisms of uremic inhibition of phagocyte reactive species production: characterization of the role of p-cresol. Kidney Int 1995;47:510-17.

68. Dou L, Cerini C, Brunet P. p-Cresol, a uremic toxin, decreases endothelial cell response to inflammatory cytokines. Kidney Int 2002;62:1999-2009.

69. Dou L, Bertrand E, Cerini C. The uremic solutes p-cresol and indoxyl sulfate inhibit endothelial proliferation and wound repair. Kidney Int 2004;65:442-51.

70. Cerini C, Dou L, Anfosso F. p-Cresol, a uremic retention solute, alters the endothelial barrier function in vitro. Thromb Haemost 2004;92:140-50.

71. Wolin MJ, Miller TL, Yerry S. Changes of fermentation pathways of fecal microbial communities associated with a drug treatment that increases dietary starch in the human colon. Appl Environ Microbiol 1999;65:2807-12.

72. Weaver GA, Tangel CT, Krause JA. Acarbose enhances human colonic butyrate production. J Nutr 1997;127:717-23.

73. Kast RE. Acarbose related diarrhea: increased butyrate upregulates prostaglandin E. Inflamm Res 2002;51:117-18

74. Vince AJ, Mcneil NI, Wager JD, et al. The effect of lactulose, pectin, arabinogalactan and cellulose on the production of organic acids and metabolism of ammonia by intestinal bacteria in a faecal incubation system. Br J Nutr 1990;63:17-26.

75. Vince AJ, Burrigde SM. Ammonia production by intestinal bacteria: the effects of lactose, lactulose and glucose. J Med Microbiol 1980;13:177-91.

76. Vince A, Killingsley M, Wrong OM. Effect of lactulose on ammonia production in a fecal incubation system. Gastroenterology 1978;74:544-9.

77. Vince A, Dawson AM, Park N, et al. Ammonia production by intestinal bacteria. Gut 1973;14:171-7.

78. Macfarlane GT, Cummings $\mathrm{JH}$. The colonic flora, fermentation and large bowel digestive function. New York: Raven Press, 1991;51-92.

79. Reuser AJ, Wisselaar HA. An evaluation of the potential side-effects of alfa-glucosidase inhibitors used for the management of diabetes mellitus. Eur J Clin Invest 1994:24:19-24.

80. Harrower AD. Pharmacokinetics of oral antihyperglycemic agents in patients with renal insufficiency. Clin Pharmacokinet 1996:31:111-19.

81. Hillebrand I, Boehme K, Frank G, et al. The effects of the alpha-glucosidase inhibitor BAY g 5421 (Acarbose) on postprandial blood glucose, serum insulin, and triglyceride levels: dose-time-response relationships in man. Res Exp Med (Berl) 1979:175:87-94

82. Baron $A D$, Eckel $\mathrm{RH}$, Schmeiser $\mathrm{L}$, et al. The effect of short-term $\alpha$-glucosidase inhibition on carbohydrate and lipid metabolism in type II (noninsulin-dependent) diabetics. Metabolism 1987;36:409-15

83. Walter-Sack IE, Wolfram G, Zollner N. Effects of acarbose on serum lipoproteins in healthy individuals during prolonged administration of a fiber-free formula diet. Ann Nutr Metab 1989;33:100-7.

84. Reaven GM, Lardinois CK, Greenfield MS, et al. Effect of acarbose on carbohydrate and lipid metabolism in NIDDM patients poorly controlled by sulfonylureas. Diabetes Care 1990;13(Suppl 3):32-6.

85. Hanefeld M, Fischer S, Schulze J, et al. Therapeutic potentials of acarbose as first-line drug in NIDDM insufficiently treated with diet alone. Diabetes Care 1991;14:732-7.

86. Leonhardt W, Hanefeld M, Fischer S, et al. Efficacy of alphaglucosidase inhibitors on lipids in NIDDM subjects with moderate hyperlipidaemia. Eur J Clin Invest 1994;24(Suppl 3):45-9.

87. Kado S, Murakami T, Aoki A, et al. Effect of acarbose on postprandial lipid metabolism in type 2 diabetes mellitus. Diabetes Res Clin Pract 1998:41:49-55.

88. Twickler TB, Dallinga-Thie G, Cohn JS, et al. Elevated remnant-like particle cholesterol concentration: a characteristic feature of the atherogenic lipoprotein phenotype. Circulation 2004;109:1918-25.

89. Ogawa S, Takeuchi K, Ito S. Acarbose lowers serum triglyceride and postprandial chylomicron levels in type 2 diabetes. Diabetes Obes Metab 2004;6:384-90.

90. Derosa G, Maffioli P, Ferrari I, et al. Acarbose actions on insulin resistance and inflammatory parameters during an oral fat load. Eur J Pharmacol 2011;651:240-50.

91. Derosa G, Maffioli P, D'angelo A, et al. Acarbose on insulin resistance after an oral fat load: a double-blind, placebo controlled study. J Diabetes Complications 2011;25:258-66. 
92. Koyasu M, Ishii $\mathrm{H}$, Watarai $\mathrm{M}$, et al. Impact of acarbose on carotid intima-media thickness in patients with newly diagnosed impaired glucose tolerance or mild type 2 diabetes mellitus: a one-year, prospective, randomized, open-label, parallel-group study in Japanese adults with established coronary artery disease. Clin Ther 2010;32:1610-17.

93. Chiasson JL, Josse RG, Gomis R, et al. Acarbose treatment and the risk of cardiovascular disease and hypertension in patients with impaired glucose tolerance: the STOP-NIDDM trial. JAMA 2003;290:486-94.

94. Hoffmann J, Spengler M. Efficacy of 24-week monotherapy with acarbose, metformin, or placebo in dietary-treated NIDDM patients: the Essen-II Study. Am J Med 1997;103:483-90.

95. Willms B, Ruge D. Comparison of acarbose and metformin in patients with Type 2 diabetes mellitus insufficiently controlled with diet and sulphonylureas: A randomized, placebo-controlled study. Diabet Med 1999;16:755-61.

96. Monami M, Vitale V, Ambrosio M, et al. Effects on lipid profile of dipeptidyl peptidase 4 inhibitors, pioglitazone, acarbose, and sulfonylureas: meta-analysis of placebo-controlled trials. Adv Ther 2012;29:736-46.

97. Malaguarnera M, Giugno I, Ruello P, et al. Treatment of familial hypertriglyceridaemia with acarbose. Diabetes Obes Metab 2000;2:33-8

98. Tan M, Wai D, Chng CL, et al. Acarbose is an effective treatment for severe hypertriglyceridemia secondary to l-asparaginase and dexamethasone. Leuk Lymphoma 2012;53:1245-6.

99. Nakano T, Inoue I, Seo M, et al. Acarbose attenuates postprandial hyperlipidemia: investigation in an intestinal absorptive cell model. Metabolism 2009;58:583-5.

100. Nordestgaard BG, Benn M, Schnohr P, et al. Nonfasting triglycerides and risk of myocardial infarction, ischemic heart disease, and death in men and women. JAMA 2007;298:299-308.

101. Zheng M, Yang J, Shan C, et al. Effects of 24-week treatment with acarbose on glucagon-like peptide 1 in newly diagnosed type 2 diabetic patients: a preliminary report. Cardiovasc Diabetol 2013;12:73.

102. Enç F, Imeryuz N, Akin L, et al. Inhibition of gastric emptying by acarbose is correlated with GLP-1 response and accompanied by CCK release. Am J Physiol Gastrointest Liver Physiol 2001;281: G752-63.

103. Qualmann C, Nauck M, Holst J, et al. Glucagon-like peptide 1 (736 amide) secretion in response to luminal sucrose from the upper and lower gut. A study using alpha-glucosidase inhibition (acarbose). Scand J Gastroenterol 1995;30:892-6.

104. Buteau J, El-Assaad W, Rhodes CJ, et al. Glucagon-like peptide-1 prevents beta cell glucolipotoxicity. Diabetologia 2004;47:806-15.

105. Miao XY, Gu ZY, Liu $P$, et al. The human glucagon-like peptide-1 analogue liraglutide regulates pancreatic beta-cell proliferation and apoptosis via an AMPK/mTOR/P70S6K signaling pathway. Peptides 2013;39:71-9.

106. Xiong $X$, Shao $W$, Jin T. New insight into the mechanisms underlying the function of the incretin hormone glucagon-like peptide-1 in pancreatic beta-cells: the involvement of the Wnt signaling pathway effector beta-catenin. Islets 2012;4:359-65.

107. Shimoda M, Kanda Y, Hamamoto S, et al. The human glucagon-like peptide-1 analogue liraglutide preserves pancreatic beta cells via regulation of cell kinetics and suppression of oxidative and endoplasmic reticulum stress in a mouse model of diabetes. Diabetologia 2011;54:1098-108.

108. Wang HW, Mizuta M, Saitoh Y, et al. Glucagon-like peptide-1 and candesartan additively improve glucolipotoxicity in pancreatic beta-cells. Metabolism 2011;60:1081-9.

109. Ding L, Zhang J. Glucagon-like peptide-1 activates endothelial nitric oxide synthase in human umbilical vein endothelial cells. Acta Pharmacol Sin 2012;33:75-81.

110. Gaspari T, Liu H, Welungoda I, et al. A GLP-1 receptor agonist liraglutide inhibits endothelial cell dysfunction and vascular adhesion molecule expression in an ApoE-/- mouse model. Diab Vasc Dis Res 2011;8:117-24.

111. Hattori $Y$, Jojima T, Tomizawa A, et al. RETRACTED ARTICLE: A glucagon-like peptide-1 (GLP-1) analogue, liraglutide, upregulates nitric oxide production and exerts anti-inflammatory action in endothelial cells. Diabetologia 2010;53:2256-63.

112. Krasner NM, Ido Y, Ruderman NB, et al. Glucagon-like peptide-1 (GLP-1) analog liraglutide inhibits endothelial cell inflammation through a calcium and AMPK dependent mechanism. PLoS ONE 2014;9:e97554.

113. Ben-Shlomo S, Zvibel I, Shnell M, et al. Glucagon-like peptide-1 reduces hepatic lipogenesis via activation of AMP-activated protein kinase. J Hepatol 2011;54:1214-23.
114. Svegliati-Baroni G, Saccomanno S, Rychlicki C, et al. Glucagon-like peptide-1 receptor activation stimulates hepatic lipid oxidation and restores hepatic signalling alteration induced by a high-fat diet in nonalcoholic steatohepatitis. Liver Int 2011;31:1285-97.

115. Lee J, Hong SW, Rhee EJ, et al. GLP-1 Receptor Agonist and Non-Alcoholic Fatty Liver Disease. Diabetes Metab J 2012;36:262-7.

116. Trevaskis JL, Griffin PS, Wittmer C, et al. Glucagon-like peptide-1 receptor agonism improves metabolic, biochemical, and histopathological indices of nonalcoholic steatohepatitis in mice. Am J Physiol Gastrointest Liver Physiol 2012;302:G762-72.

117. Cuthbertson DJ, Irwin A, Gardner CJ, et al. Improved glycaemia correlates with liver fat reduction in obese, type 2 diabetes, patients given glucagon-like peptide-1 (GLP-1) receptor agonists. PLoS ONE 2012;7:e50117.

118. Eguchi $\mathrm{Y}$, Kitajima $\mathrm{Y}$, Hyogo $\mathrm{H}$, et al. Pilot study of liraglutide effects in non-alcoholic steatohepatitis and non-alcoholic fatty liver disease with glucose intolerance in Japanese patients (LEAN-J). Hepatol Res 2015;45:269-78.

119. Yamagishi S, Nakamura $\mathrm{K}$, Inoue $\mathrm{H}$. Acarbose is a promising therapeutic strategy for the treatment of patients with nonalcoholic steatohepatitis (NASH). Med Hypotheses 2005;65:377-9.

120. Bose AK, Mocanu MM, Carr RD, et al. Glucagon like peptide-1 is protective against myocardial ischemia/reperfusion injury when given either as a preconditioning mimetic or at reperfusion in an isolated rat heart model. Cardiovasc Drugs Ther 2005;19:9-11.

121. Fields AV, Patterson B, Karnik AA, et al. Glucagon-like peptide-1 and myocardial protection: more than glycemic control. Clin Cardiol 2009;32:236-43.

122. Birnbaum $\mathrm{Y}, \mathrm{Ye} \mathrm{Y}$, Bajaj M. Myocardial protection against ischemia-reperfusion injury by GLP-1: molecular mechanisms. Metab Syndr Relat Disord 2012;10:387-90.

123. Read PA, Hoole SP, White PA, et al. A pilot study to assess whether glucagon-like peptide-1 protects the heart from ischemic dysfunction and attenuates stunning after coronary balloon occlusion in humans. Circ Cardiovasc Interv 2011;4:266-72.

124. Kai Z, Yongbo W, Lin Z, et al. Exendin-4 attenuates ischemia-induced ventricular arrhythmias in rats. Cardiol $J$ 2013;20:29-33.

125. Testai L, Rapposelli S, Calderone V. Cardiac ATP-sensitive potassium channels: a potential target for an anti-ischaemic pharmacological strategy. Cardiovasc Hematol Agents Med Chem 2007;5:79-90.

126. Yang $M$, Zhang $L$, Wang $C$, et al. Liraglutide increases FGF-21 activity and insulin sensitivity in high fat diet and adiponectin knockdown induced insulin resistance. PLoS ONE 2012;7:e48392.

127. Minatoguchi S, Zhang Z, Bao N, et al. Acarbose reduces myocardial infarct size by preventing postprandial hyperglycemia and hydroxyl radical production and opening mitochondrial KATP channels in rabbits. J Cardiovasc Pharmacol 2009;54:25-30.

128. Ritz P, Vaurs C, Bertrand M, et al. Usefulness of acarbose and dietary modifications to limit glycemic variability following Roux-en-Y gastric bypass as assessed by continuous glucose monitoring. Diabetes Technol Ther 2012;14:736-40.

129. Buscemi S, Mattina A, Genova G, et al. Seven-day subcutaneous continuous glucose monitoring demonstrates that treatment with acarbose attenuates late dumping syndrome in a woman with gastrectomy for gastric cancer. Diabetes Res Clin Pract 2013;99: e1-2.

130. Clissold S, Edwards C. Acarbose. Drugs 1988;35:214-43.

131. Coniff RF, Shapiro JA, Seaton TB. Long-term efficacy and safety of acarbose in the treatment of obese subjects with non-insulin-dependent diabetes mellitus. Arch Intern Med 1994;154:2442-8.

132. Meneilly GS, Ryan EA, Radziuk J, et al. Effect of acarbose on insulin sensitivity in elderly patients with diabetes. Diabetes Care 2000;23:1162-7.

133. Chan JC, Chan KW, Ho LL, et al. An Asian multicenter clinical trial to assess the efficacy and tolerability of acarbose compared with placebo in type 2 diabetic patients previously treated with diet. Asian Acarbose Study Group. Diabetes Care 1998;21: 1058-61

134. Pan CY, Gao Y, Chen JW, et al. Efficacy of acarbose in Chinese subjects with impaired glucose tolerance. Diabetes Res Clin Pract 2003;61:183-90.

135. Li $\mathrm{Y}$, Tong $\mathrm{Y}$, Zhang $\mathrm{Y}$, et al. Acarbose monotherapy and weight loss in Eastern and Western populations with hyperglycaemia: an ethnicity-specific meta-analysis. Int J Clin Pract 2014;68:1318-32.

136. Lean ME, Powrie JK, Anderson AS, et al. Obesity, weight loss and prognosis in type 2 diabetes. Diabet Med 1990;7:228-33. 
137. Wing RR, Lang W, Wadden TA, et al, Look AHEAD Research Group. Benefits of modest weight loss in improving cardiovascular risk factors in overweight and obese individuals with type 2 diabetes. Diabetes Care 2011;34:1481-6.

138. Chiasson J, Josse R, Gomis R, et al. Acarbose for prevention of type 2 diabetes mellitus: the STOP-NIDDM randomised trial. Lancet 2002;359:2072-7.

139. Hanefeld M, Cagatay M, Petrowitsch T, et al. Acarbose reduces the risk for myocardial infarction in type 2 diabetic patients: meta-analysis of seven long-term studies. Eur Heart $J$ 2004;25:10-16.

140. Holman RR, Bethel MA, Chan JC, et al. Rationale for and design of the Acarbose Cardiovascular Evaluation (ACE) trial. Am Heart $J$ 2014;168:23-9.e2

141. Holman R. Acarbose Cardiovascular Evaluation Trial (ACE). 2014;2015(March 17)

142. Harrison DE, Strong R, Allison DB, et al. Acarbose, 17- $\alpha$-estradiol, and nordihydroguaiaretic acid extend mouse lifespan preferentially in males. Aging Cell 2014;13:273-82.

143. Bartke A. Minireview: role of the growth hormone/insulin-like growth factor system in mammalian aging. Endocrinology 2005;146:3718-23.

144. Inagaki T, Lin VY, Goetz R, et al. Inhibition of growth hormone signaling by the fasting-induced hormone FGF21. Cell Metab 2008;8:77-83

145. Yu J, Zhao L, Wang A, et al. Growth hormone stimulates transcription of the fibroblast growth factor 21 gene in the liver through the signal transducer and activator of transcription 5 . Endocrinology 2012;153:750-8.

146. Kralisch S, Tönjes A, Krause K, et al. Fibroblast growth factor-21 serum concentrations are associated with metabolic and hepatic markers in humans. J Endocrinol 2013;216:135-43.

147. Mendelsohn AR, Larrick JW. Fibroblast growth factor-21 is a promising dietary restriction mimetic. Rejuvenation Res 2012;15:624-8.

148. Zhang $\mathrm{Y}, \mathrm{Xie} \mathrm{Y}$, Berglund ED, et al. The starvation hormone, fibroblast growth factor-21, extends lifespan in mice. Elife 2012;1: e00065.

149. Seifarth C, Bergmann J, Holst JJ, et al. Prolonged and enhanced secretion of glucagon-like peptide 1 (7-36 amide) after oral sucrose due to alpha-glucosidase inhibition (acarbose) in Type 2 diabetic patients. Diabet Med 1998;15:485-91.

150. Nonogaki K, Hazama M, Satoh N. Liraglutide suppresses obesity and hyperglycemia associated with increases in hepatic fibroblast growth factor 21 production in KKAy mice. Biomed Res Int 2014;2014:751930.

151. Li Y, Wong K, Giles A, et al. Hepatic SIRT1 attenuates hepatic steatosis and controls energy balance in mice by inducing fibroblast growth factor 21. Gastroenterology 2014;146:539-49. e537.

152. Purushotham A, Schug TT, Xu Q, et al. Hepatocyte-specific deletion of SIRT1 alters fatty acid metabolism and results in hepatic steatosis and inflammation. Cell Metab 2009;9:327-38.

153. Lundasen T, Hunt MC, Nilsson LM, et al. PPARalpha is a key regulator of hepatic FGF21. Biochem Biophys Res Commun 2007:360:437-40.

154. Ong KL, Rye KA, O'connell R, et al. Long-term fenofibrate therapy increases fibroblast growth factor 21 and retinol-binding protein 4 in subjects with type 2 diabetes. J Clin Endocrinol Metab 2012;97:4701-8.

155. Galman C, Lundasen T, Kharitonenkov A, et al. The circulating metabolic regulator FGF21 is induced by prolonged fasting and PPARalpha activation in man. Cell Metab 2008;8 169-74.

156. Pachikian BD, Essaghir A, Demoulin JB, et al. Prebiotic approach alleviates hepatic steatosis: implication of fatty acid oxidative and cholesterol synthesis pathways. Mol Nutr Food Res 2013;57:347-59.
157. Rosak C, Mertes G. Critical evaluation of the role of acarbose in the treatment of diabetes: patient considerations. Diabetes Metab Syndr Obes 2012;5:357-67.

158. Buse J, Hart K, Minasi L. The PROTECT Study: final results of a large multicenter postmarketing study in patients with type 2 diabetes. Precose Resolution of Optimal Titration to Enhance Current Therapies. Clin Ther 1998:20:257-69.

159. Spengler M, Schmitz H, Landen $\mathrm{H}$. Evaluation of the efficacy and tolerability of acarbose in patients with diabetes mellitus : a postmarketing surveillance study. Clin Drug Investig 2005;25:651-9.

160. Mertes G. Safety and efficacy of acarbose in the treatment of Type 2 diabetes: data from a 5-year surveillance study. Diabetes Res Clin Pract 2001;52:193-204.

161. Li C, Hung YJ, Qamruddin K, et al. International noninterventional study of acarbose treatment in patients with type 2 diabetes mellitus. Diabetes Res Clin Pract 2011;92:57-64.

162. Pan $\mathrm{CY}$, Landen $\mathrm{H}$. Post-marketing surveillance of acarbose treatment in patients with type 2 diabetes mellitus and subjects with impaired glucose tolerance in China. Clin Drug Investig 2007:27:397-405.

163. Fischer S, Hanefeld M, Spengler M, et al. European study on dose-response relationship of acarbose as a first-line drug in non-insulin-dependent diabetes mellitus: efficacy and safety of low and high doses. Acta Diabetol 1998;35:34-40.

164. Santeusiano F, Ventura M, Contadini S, et al. Efficacy and safety of two different dosages of acarbose in non-insulin dependent diabetic patients treated by diet alone. Diabetes Nutr Metab 1993:6:147-54.

165. Radziuk J, Kemmer F, Morishima T, et al. The effects of an alpha-glucoside hydrolase inhibitor on glycemia and the absorption of sucrose in man determined using a tracer method. Diabetes 1984;33:207-13.

166. May C. Wirksamkeit und Verträglichkeit von einschleichend dosierter Acarbose bei Patienten mit nichtinsulinpflichtigem Diabetes mellitus unter Sulfonylharnstofftherapie (German). Diabetes Stoffwechsel 1995:4:3-8.

167. Creutzfeldt W, Folsch UR, Elsenhans B, et al. Adaptation of the small intestine to induced maldigestion in rats. Experimental pancreatic atrophy and acarbose feeding. Scand J Gastroenterol Supp/ 1985; 112:45-53.

168. Koytchev R, Richter W, Erkent U, et al. Influence of acarbose on blood glucose and breath hydrogen after carbohydrate load with sucrose or starch. Arzneimittelforschung 2009;59:557-63.

169. Ahr HJ, Krause HP, Siefert HM, et al. Pharmacokinetics of acarbose. Part II: Distribution to and elimination from tissues and organs following single or repeated administration of [14C]acarbose to rats and dogs. Arzneimittelforschung 1989;39:1261-7.

170. Salvatore T, Giugliano D. Pharmacokinetic-pharmacodynamic relationships of Acarbose. Clin Pharmacokinet 1996;30:94-106.

171. Coniff R, Krol A. Acarbose: a review of US clinical experience. Clin Ther 1997;19:16-26; discussion 12-13.

172. Lebovitz $\mathrm{H}$. Alpha-glucosidase-inhibitors as agents in the treatment of type 2 diabetes. Diabetes Rev 1998;6:132-45.

173. Haupt E, Hillebrand I, Pfeffer $\mathrm{H}$. Effectiveness and tolerability of the $\alpha$-glucosidase inhibitor acarbose in NIDDM patients with elevated liver enzyme activity. In: Creutzfeldt W, ed. Acarbose for the treatment of diabetes mellitus. Springer Berlin Heidelberg, 1988:135-135

174. Zillikens MC, Swart GR, Van Den Berg JW, et al. Effects of the glucosidase inhibitor acarbose in patients with liver cirrhosis. Aliment Pharmacol Ther 1989;3:453-9.

175. Kihara $Y$, Ogami $Y$, Tabaru A, et al. Safe and effective treatment of diabetes mellitus associated with chronic liver diseases with an alpha-glucosidase inhibitor, acarbose. J Gastroenterol 1997;32:777-82.

176. Bayer HealthCare Pharmaceuticals Inc. Precose (acarbose tablets). 2015(March 19), (2011). 